\title{
Ventriculoperitoneal Shunt Survival in Pediatric Patients and Future Prospects
}

\section{Farid Khan}

Neurosurgery, The Aga Khan University Medical College, Stadium Road-74800, Karachi, Pakistan

*Corresponding author: Farid Khan, Neurosurgery, The Aga Khan University Medical College, Stadium Road-74800, Karachi, Pakistan, Tel: +92 321358 1733; E-mail: drfaridkhan@hotmail.com

\section{Received date: September 01, 2016; Accepted date: October 26, 2016; Published date: October 31, 2016}

Copyright: (c) 2016 Khan F. This is an open-access article distributed under the terms of the Creative Commons Attribution License, which permits unrestricted use, distribution, and reproduction in any medium, provided the original author and source are credited.

\section{Commentary}

Hydrocephalus has been observed as one of the most common pediatric neurosurgical conditions [1]. Due to progressive nature, if not treated in time, hydrocephalus can lead to significant disability and mortality [2]. Globally hydrocephalus is most commonly and traditionally treated with cerebrospinal fluid diversion with ventriculoperitoneal (VP) shunt insertion [3]. Despite its effectiveness VP shunt placement has significant shunt device as well as disease related complications. Most commonly observed complications include shunt obstruction, infection, dislocation, breakage and functional failure such as overdrainage $[4,5]$.

Endoscopic third ventriculostomy (ETV) is another method of treatment with the advantage of cost-effectiveness and also devoid of shunt device complications [6,7]. But due to its limitations of questionable effectiveness in certain etiologies, unavailability of expertise and requisite of advanced imaging make this modality less preferred choice of surgery $[8,9]$.

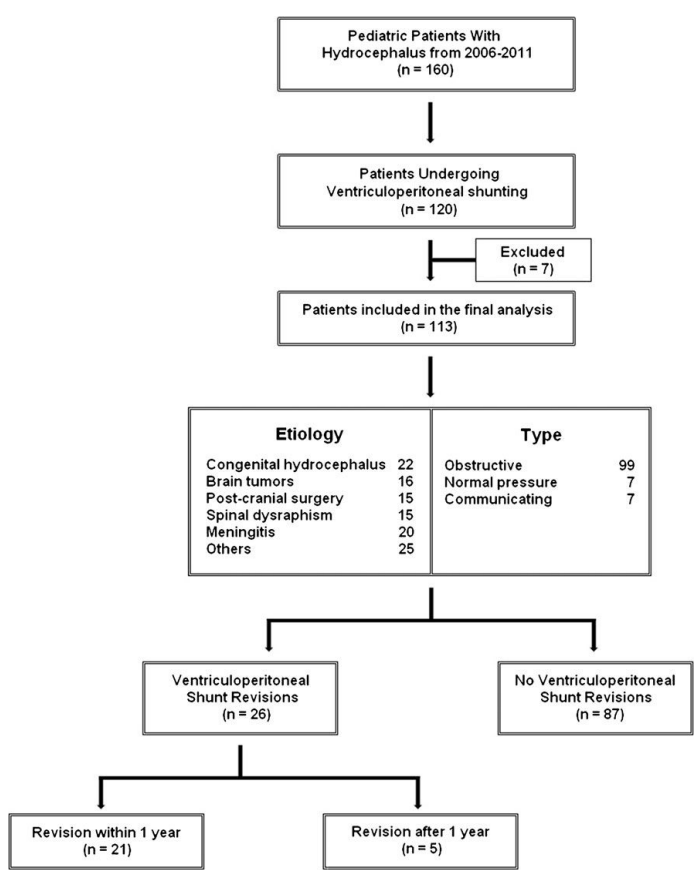

Figure 1: A flow diagram depicting the selection of patients for inclusion in the final analysis along with a summary of the etiologies and types of hydrocephalus and subsequent initial and revision ventriculoperitoneal shunt insertion.
This study reports a retrospective data of 6 years from 2006 to 2011 (Figure 1). Experience with hydrocephalus and its management with VP shunt surgery of a single center in a developing country was observed. Special effort was made to retrieve a detailed data pertaining to initial patient encounter before shunt surgery to the last outpatient follow-up or inpatient activity. All of the patients included in the study underwent VP shunting only, the primary modality of treatment available at this center.

\begin{tabular}{|l|c|c|c|}
\hline Etiology & $\begin{array}{c}\text { Patients } \\
(\mathbf{n = 1 1 3 )}\end{array}$ & $\begin{array}{c}\text { Patients with shunt } \\
\text { malfunction (n=26) }\end{array}$ & p-value \\
\hline Congenital hydrocephalus & $22(19.5 \%)$ & $6(23.1 \%)$ & 0.596 \\
\hline Brain tumor & $16(14.2 \%)$ & $1(3.8 \%)$ & 0.084 \\
\hline Post-cranial surgery & $15(13.3 \%)$ & $3(11.5 \%)$ & 0.766 \\
\hline Spinal dysraphism & $15(13.3 \%)$ & $3(11.5 \%)$ & 0.766 \\
\hline Bacterial meningitis & $11(9.7 \%)$ & $5(19.2 \%)$ & 0.063 \\
\hline Tuberculous meningitis & $9(8.0 \%)$ & $2(7.7 \%)$ & 0.953 \\
\hline Idiopathic & $6(5.3 \%)$ & $2(7.7 \%)$ & 0.537 \\
\hline Post-meningitis* & $4(3.5 \%)$ & $0(0 \%)$ & 0.266 \\
\hline $\begin{array}{l}\text { Intraventricular } \\
\text { hemorrhage }\end{array}$ & $3(2.7 \%)$ & $1(3.8 \%)$ & 0.667 \\
\hline Traumatic brain injury & $2(1.8 \%)$ & $0(0 \%)$ & 0.435 \\
\hline Aqueductal stenosis & $2(1.8 \%)$ & $1(3.8 \%)$ & 0.36 \\
\hline $\begin{array}{l}\text { Arnold-Chiari } \\
\text { malformation }\end{array}$ & $2(1.8 \%)$ & $0(0 \%)$ & 0.435 \\
\hline Vascular malformation & $1(0.9 \%)$ & $0(0 \%)$ & 0.583 \\
\hline Intracerebral hemorrhage & $1(0.9 \%)$ & $0(0 \%)$ & 0.583 \\
\hline $\begin{array}{l}\text { Dandy-Walker } \\
\text { malformation }\end{array}$ & $1(0.9 \%)$ & $0(0 \%)$ & 0.583 \\
\hline Arachnoid cyst & $1(0.9 \%)$ & $1(3.8 \%)$ & 0.066 \\
\hline Encephalocele & $1(0.9 \%)$ & $1(3.8 \%)$ & 0.066 \\
\hline Congenital hygroma & $1(0.9 \%)$ & $0(0 \%)$ & 0.583 \\
\hline
\end{tabular}

Table 1: Etiologies of hydrocephalus with shunt malfunction $\left({ }^{\star} \mathrm{Other}\right.$ than bacterial or tuberculous meningitis).

Contrary to preexisting traditional shunt related studies, this study not only analyzed etiologies (Table 1) shunt complications and contributing factors but also observed shunt survival as well (Figure 2). 
Page 2 of 2

Emphasis to VP shunt survival was given to find median time to first shunt failure and various factors contributing to early shunt failure. This type of approach makes our study one of the uplifting reports newly added to the literature of pediatric hydrocephalus.

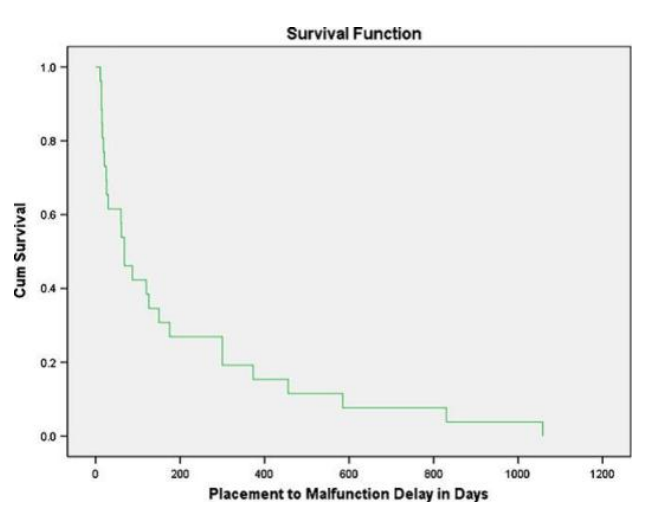

Figure 2: Kaplan-Meier shunt survival analysis for pediatric hydrocephalus shows that overall median time to first shunt failure was 68 days with shunt survival time ranging from 11 to 1,058 days; out of 26 shunt failures, 23 occurred before 500 days.

Elaborate use of Kaplan-Meier survival curves showed shunt failure rates of $18.58 \%$ and $20.35 \%$ at 1 year and 500 days, respectively. Miscellaneous factors contributing to early shunt failure such as certain etiologies of hydrocephalus, presence of meningitis, congenital anomalies (Figure 3), past history of mass lesion and mass excision, were identified.

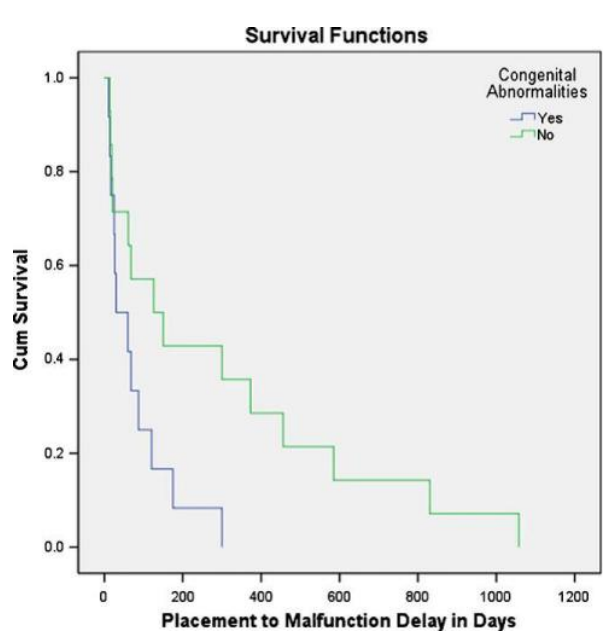

Figure 3: Kaplan-Meier shunt survival analysis for pediatric hydrocephalus shows that the presence of congenital abnormalities had a significant influence on the median time to first shunt failure $(\mathrm{p}=0.031, \log$ rank).

An interesting observation was early shunt malfunction among children who were delivered via Caesarean sections as compared to those who were delivered via normal vaginal births. Though data for a number of patients' mode of delivery were missing, this observation still encourages researchers to explore further whether mode of delivery impacts median time to shunt failure. This report also confirms that VP shunt insertion in children born preterm is still a huge challenge and burden of care due to increased complications.

All VP shunt procedures were performed in separate sessions after repairing midline defects and spinal dysraphism, which might have contributed to low rate of shunt complications in our study. The same observation was reported by Oktem et al. [10]. It should pave the way for neurosurgical centers to adopt this strategy in practice after carefully evaluating cost and feasibility. Interestingly, we also observed that strict aseptic surgical techniques and availability of expertise played a huge role in reducing the incidence of shunt malfunction.

Our study, despite being conducted in a developing country setting and owning certain shortcomings such as missing data and patients lost to follow up, is one of the few from the South Asian countries that comprehensively assessed numerous determinants of VP shunt survival in pediatric patients.

Based on our experience we encourage readers to establish rigorous periodic evaluation of post-shunt surgery status of patients and shunt function in outpatient setting, especially those at high risk for shunt failure. This will help in documentation of clinical progress and timely intervention. We hope that hydrocephalus and shunt research in future will avidly consider the impact of prematurity and congenital abnormalities on shunt survival.

\section{References}

1. Muir RT, Wang S, Warf BC (2016) Global surgery for pediatric hydrocephalus in the developing world: A review of the history, challenges and future directions. Neurosurg Focus 41: E11.

2. Paulsen AH, Lundar T, Lindegaard KF (2010) Twenty-year outcome in young adults with childhood hydrocephalus: assessment of surgical outcome, work participation and health-related quality of life. J Neurosurg Pediatr 6: 527-535.

3. Reddy GK, Bollam P, Shi R, Guthikonda B, Nanda A (2011) Management of adult hydrocephalus with ventriculoperitoneal shunts: Long-term single-institution experience. Neurosurgery 69: 774-800.

4. Drake JM, Kestle JRW, Milner R, Cinalli G, Boop F, et al. (1998) Randomized trial of cerebrospinal fluid shunt valve design in pediatric hydrocephalus. Neurosurgery 43: 294-303.

5. Drake JM, Sainte-Rose C (1995) The shunt book: Blackwell Science, Cambridge, UK.

6. Jallo GI, Kothbauer KF, Abbott IR (2005) Endoscopic third ventriculostomy. Neurosurg Focus 19: E11.

7. Di Rocco C, Massimi L, Tamburrini G (2006) Shunts vs. endoscopic third ventriculostomy in infants: Are there different types and/or rates of complications? A review. Childs Nerv Syst 22: 1573-1589.

8. Mohanty A, Vasudev MK, Sampath S, Radhesh S, Kolluri VRS (2002) Failed endoscopic third ventriculostomy in children: Management options. Pediatr Neurosurg 37: 304-309.

9. Emejulu JKC, Ugwu JO (2009) Combating complications following ventriculoperitoneal shunting in a new centre. Pediatr Neurosurg 45: 446-450.

10. Oktem IS, Menkü A, Ozdemir A (2008) When should ventriculoperitoneal shunt placement be performed in cases with myelomeningocele and hydrocephalus? Turk Neurosurg 18: 387-391. 